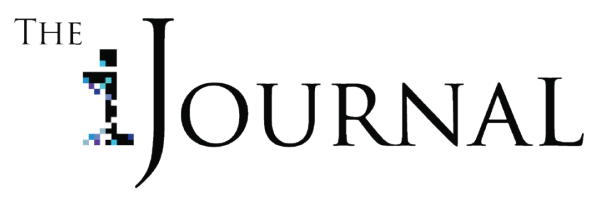

\title{
Resisting Linear Form: Sterne and Phillips with "nothing between them but / time"
}

\section{Leora Bromberg}

\begin{abstract}
Readers have certain expectations. Out of any given narrative, we expect an introduction, body, and conclusion. English words should flow logically, one after the other, running from the left to right, and in straight lines along the page. Any interruption to this linear process of reading may draw out a range of emotional responses, whether it be confusion, anger, awe, or insight. Early resistance to a linear reading experience is evident in Laurence Sterne's 1759-1767 novel The Life and Opinions of Tristram Shandy, Gentleman. Unfolding over the course of nine volumes, this narrative is frequently interrupted with unusual visual and typographic experiments that remain puzzling and intriguing to readers to this day. Likely the most expensive and ambitious of Sterne's experiments is the third volume's marbled page-a single page coated front and back in a layer of marbled paint, painstakingly and seamlessly constrained within the margins of the text-block. This paper explores the impact of these experiments on the reading experience, with particular attention to the marbled page and looking towards the reception of Sterne in the contemporary work of book artist Tom Phillips. Despite being raised in the same discussions as examples of works that are intensely aware of their own form, there appears to be little analysis of the connection between Sterne and Phillips. Exploring the reception of Sterne in Phillips' A Humument illuminates not only how Phillips references Sterne, but also how the very form and design of his work emulates a similar resistance to the linearity of reading and literate culture.
\end{abstract}

\section{Keywords}

Laurence Sterne, marbled page, Tom Phillips, literate culture, linearity, reception 


\section{Bromberg / Resisting Linear Form}

\section{INTRODUCTION}

A dark and blackened space, blots of intermingling colours, emptiness, and twisting lines: while perhaps evoking an emotional experience, or meriting some other interpretation, these sensory displays take physical form on the pages of Laurence Sterne's 1759-1767 literary masterpiece, The Life and Opinions of Tristram Shandy, Gentleman (Tristram Shandy). As readers progress through the nine volumes of Sterne's novel, they will discover pages where the text-block is entirely blacked out, transformed into a colourful marbled surface, left blank, or filled with squiggling lines - among several other unusual visual and typographical interruptions to the narrative. Even two hundred and sixty years later, these printing experiments remain puzzling and marvelous, stimulating various interpretations from literary scholars and book historians who have even dedicated their life's work to deconstructing and investigating Sterne's visions. A closer reading of some interpretations of the visual experiments in Tristram Shandy, with close attention to the third volume's marbled page, curiously reveals how Sterne's novel is often discussed alongside the contemporary work of book artist Tom Phillips. Phillips' own longterm visual and textual experiments, in his book A Humument, not only make explicit allusions to Sterne, but also emulate, as this paper suggests, similar resistance to linearity and literate culture in its form and design. Despite this apparent tendency for Sterne and Phillips to come up in the same discussions, there seems to be surprisingly little analysis of their connection (De Voogd, 1988; Portela, 2014). A closer analysis of Phillips' work illuminates a lasting and parallel message to be found in Sterne's: a culture which strives for precision and order cannot entirely eliminate randomness and singularity, where beauty, emotion, and meaning can be found and sometimes, even words can fail to express.

\section{PAPER-MARBLING AND STERNE'S MARBLED PAGE}

The unusual marbled page in the third volume of Sterne's Tristram Shandy stands out as perhaps the most ambitious of all his print experiments throughout the novel, in terms of both cost and technical skill. Yet, even the traditional process of hand-marbling paper is already complicated, time-consuming, and expensive. The process begins with a thick liquid solution called "size", onto which blobs of different colours of paint are suspended and manipulated to create a pattern. This pattern is then transferred onto paper through absorption, rinsed and hung to dry (Wolfe, 1991, p. 2). According to Wolfe (1991), this process requires a lot of patience and training, since it could be easily disturbed by external factors generally beyond the marbler's control, such as fluctuations in temperature, humidity, the fluidity or viscosity of the size, and chemical interferences with the pigments (p. 2). Given that this basic technique results in any given sheet coated edge to edge in blots and swirls of paint, marbled paper generally seems to best serve more decorative purposes, such as on the covers of books.

Sterne's marbled page diverges from and greatly complicates this basic marbling technique. Sterne not only decided to insert a marbled sheet into the middle of his text, right at the end of the thirty-sixth chapter (Sterne, 1761, p. 169-170), but he even insisted that the marbling remain within the margins of the text-block - on both the recto (front) and verso (back) of this single sheet. Creating just one of these double-sided marbled sheets would have required cutting the paper to match the book's small duodecimo size, measuring and folding the margins back carefully to expose only the text-block, dipping one side onto a carefully prepared marbled 


\section{Bromberg / Resisting Linear Form}

solution, hanging it to dry, and then having to repeat the same steps for the other side (De Voogd, 2018, p. 76). Indeed, fold marks along the margins are still evident on this page in extant original editions of this volume (Sterne, 1761, p. 169-170). Finally, to blend it in with the book's format, the page numbers were stamped on by hand (De Voogd, 2018, p. 76). Although this already sounds like a great deal of extra effort, the complexity of producing this single leaf cannot be fully understood without considering that the first edition of the third volume had a print run of approximately 4,500 copies. Therefore, the production of this single leaf would have required a total of 9,000 separate sizing, folding, marbling, and stamping operations (De Voogd, 2018, p. 76). Not to mention the fact that in order to keep up with such a large print run, the marbling solution and colours had to be refreshed periodically (Day, 1972, p. 145). The production of this single page, among other visual and textual experiments throughout the novel, suggests that Sterne evidently went above and beyond his role as an author to envision the material features of his book and exert a great deal of control over the printing process.

When the third volume of Tristram Shandy was released in 1761, paper-marbling was still quite new to England. Although it flourished in Turkey and the Middle East, the practice of marbling paper first became known to Europeans only around the sixteenth and seventeenth centuries. In England, it came into use later, towards the end of the eighteenth century (Wolfe, 1991, p. 73). Today, the marbled aesthetic certainly feels distant if not entirely unfamiliar, largely due to mechanization and by consequence, a decreased demand for this craft. Indeed, in his exploration of the history of marbled paper, Wolfe (1991) reflects that "few people today are aware of the considerable role that marbled paper played in the everyday life of Europe and the Western World from late in the seventeenth century until late in the nineteenth" (p. 1). As a result, even fewer are "in a position to appreciate the enormous contribution that marbling has made to the overall history of the book" (Wolfe, 1991, p. 1). Perhaps Sterne's novel would have been met with a similar lack of awareness and appreciation for this craft in its own time, given that at this point, English readers may not have become fully accustomed to seeing marbled paper on books, let alone inside them. This aligns with De Voogd (1985), who imagines that this page and the novel more broadly, "must have been startling, totally original and quite baffling" at the time (De Voogd, 1985, p. 285).

Indeed, the originality of this visual experiment can be better grasped when considering that this hand-marbled sheet alone distinguishes every copy of the third volume. In other words, the marbled page has a 'snowflake effect' on the book, causing no two copies to be identical. What is so special about these messy blots of colour? Perhaps nothing. Wolfe (1991) suggests that the uniqueness of this page does not stem from the quality of the marbling itself. This is evident when he argues that the marbled leaf was "a modest effort, not like anything made abroad at the time, and not very handsome or well-executed at that" (p. 70). Instead, Sterne's marbled page displays this craft as a "curiosity and a novelty" in England at the time and uses it as a disruptive technique (Wolfe, 1991, p. 70). The unique nature of this page is even further reinforced by the fact that when faced with the expense and challenge of reproducing this page, subsequent reprints either inserted a copy of an original marbled page, pasted in manufactured marbled paper, or simply left an explanation like "a marbled leaf was inserted here"-if not omitting it altogether (Figure 1) (De Voogd, 1985, p. 285). Such reprints failed to appreciate how the marbled page served a crucial artistic purpose in rendering each copy unique. As suggested through the analysis which follows, the marbled page not only functions to render each copy unique, but through its inherently random and disorderly design, it also actively resists the linear 
Bromberg / Resisting Linear Form

constraints of literate and print culture.

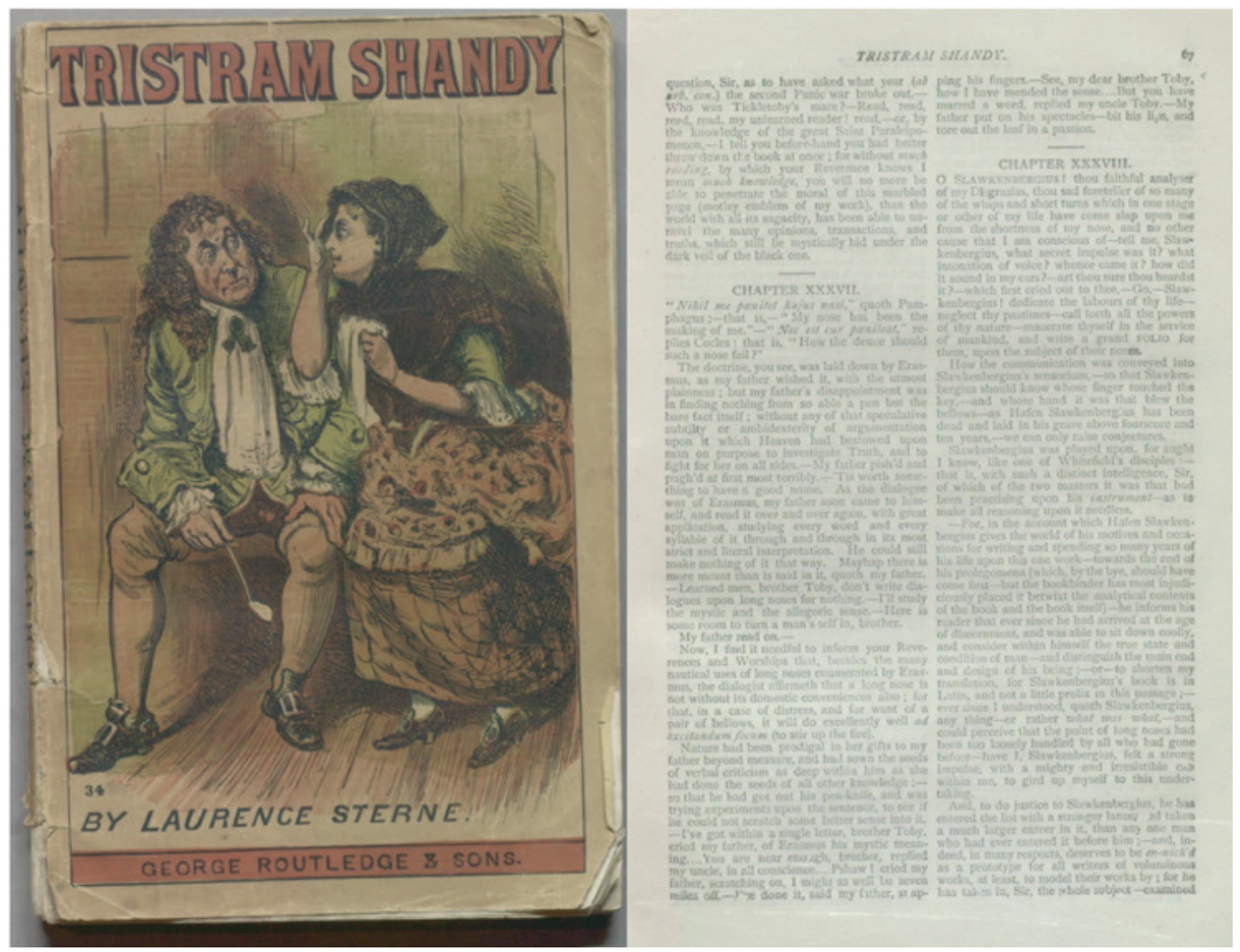

Figure 1: This 1883 yellowback reprint of Tristram Shandy omits the marbled page altogether, jumping straight to chapter XXXVII despite still including the lines that introduce the marbled page (Sterne, 1883, 67). Thomas Fisher Rare Book Library.

\section{READING THE MARBLED PAGE}

While scholars seem to understand the uniqueness of the marbled page, its meaning and intention remain a curiosity. Peter De Voogd, the chair of the International Laurence Sterne Foundation (ILSF) himself, was drawn in by this page ever since first seeing an original copy (International Laurence Sterne Foundation, 2019; De Voogd, 1985, p. 284). Intrigued and puzzled by this page, scholars have offered various interpretations for how it could be 'read.' To De Voogd, the marbled leaf itself visually represents how we read. De Voogd (1985) finds comfort in the fact that the marbled leaf renders every copy unique when he writes, "it is fitting that your copy of Tristram Shandy is different from mine, since your subjective experience of the book is different and when you turn the page, the design is different again" (p. 287). Here, De Voogd equates the variation of each marbling with the unique and subjective nature of every reading experience. He goes on to stipulate that this page is "neither an end sheet, nor without meaning," as if its role in the reading experience is somewhere between passive and active (De Voogd, 1985, p. 287). This interpretation suggests that the page holds more meaning than mere decorative endpaper, but this meaning may manifest differently depending on the reader. This argument is echoed by Portela 


\section{Bromberg / Resisting Linear Form}

(2014), who likewise compares the marbled page to the "singularity of reading itself as a social and individual performance" (p. 50). To Portela (2014), the "random blots, points, and lines of color on each of the marbled pages can be read as a visualization of the indeterminacy that results from...the interaction between writing and reading" (p. 52). In other words, the abstract patterns that take form on this page require a shift in the reader's senses, from processing words to processing image.

This shift in the reader's senses is not an easy transition to make. Indeed, even within the narrative, Sterne (1761) himself seems to set up the marbled leaf as a reading challenge when he introduces it as follows:

Read, read, read, read my unlearned reader! read,- or by the knowledge of the great saint Paraleipomenon-I tell you before-hand, you had better throw down the book at once; for without much reading, by which your reverence knows, I mean much knowledge, you will no more be able to penetrate the moral of the next marbled page (motley emblem of my work!) than the world with all its sagacity has been able to unravel the many opinions, transactions and truths, which still lie mystically hid under the dark veil of the black one (p. 168).

Sterne (1761) seems to expect and even intend for the marbled page to be a frustrating interruption to the text. He teases readers with the assertion that they will not be able to break free from their normative and linear understanding of reading and knowledge of what a book is meant to look like. He even connects this to a previous full text-block visual interruption, "the black one", referring back to the blackened page in the first volume of Tristram Shandyapparently setting it up similarly as a page that can somehow be read (Sterne, 1761, p. 168; 1760, p. 73-74). From this perspective, the marbled page is at once a challenge to how we read and a representation of the act of reading itself.

Other interpretations might focus instead on the protagonist Tristram's parenthetical praise of the page as the "(motley emblem of my work!)" (Sterne, 1761, p. 168). Although this phrase refers to the fictional work of the main character, the marbled page has in fact come to be iconic and emblematic of Sterne's work. This is evident even on the covers of the Shandean, the academic journal dedicated to Sterne's life and works published annually by the ILSF, which each feature a different extant copy of the marbled page (International Laurence Sterne Foundation, 2018). This focus on the marbled page as representative of Sterne's work is curious, considering that although he "saw each new volume through the press himself," Sterne was not the marbler (De Voogd, 1988, p. 30). According to Wolfe (1991), the work of the marbler was "almost never signed." By consequence, "the very nature of the product has worked against a better understanding of it" (Wolfe, 1991, p. 1). Regardless, the page being hand-made and unique each time appears to have been important to Sterne's own vision. If this page is emblematic of this work, then perhaps Sterne himself wanted to remind readers of the material features of the book as a medium.

To Portela (2014), the physical and material features of the book play an essential role in the act of reading. He turns to Tristram Shandy as a good example of this, calling it a "metabook", given that its visual and textual experiments each serve as a "self-reflection on its own formal and social materiality as a codex" (Portela, 2014, p. 44). To support this claim, Portela (2014) offers that the marbled page serves to recall marbled endpapers, stimulating the readers to consider the materiality of the book (p. 51). This is a claim seen elsewhere, such as when Barchas (2013) assumes readers would have recognized the famous marbled page as "misplaced endpapers" (p. 16). However, as De Voogd (1985) points out, this argument is 


\section{Bromberg / Resisting Linear Form}

"historically incorrect" since end sheets were "seldom if ever marbled" at this time, before marbling was mechanized and commercially available (p. 285). If the marbled page is therefore not necessarily emblematic of the form of the book, perhaps it can be understood as emblematic of the work's genre.

One way to better understand this page is to recall the context of this novel as a fictional autobiography, as implied by the title itself. As Romney (2014) explains, by calling this page the emblem of his work, Tristram is "drawing a direct connection between the page and his life." In other words, if the page represents the work, and the work represents him, then the marbled page becomes a reflection of the self. This perspective resonates with De Voogd (1985) when he describes the marbled page and the novel more broadly as aiming for a "literary "portrait"" of Tristram (p. 287). Romney (2014) pushes this further to conceive of the marbled page as "more than a symbol of [Sterne's] style or of the reader's experience," but rather an embodiment of "each of us." From this perspective, the marbled page functions like a mirror, reflecting the reader back to him or herself. It can be read as a visual representation not just of how we read, but of consciousness more broadly.

\section{RECEPTION OF STERNE IN THE CONTEMPORARY WORKS OF PHILLIPS}

An interesting detail that appears to reoccur across a few different studies of Sterne's work is some passing mention of A Humument: A Treated Victorian Novel, by contemporary artist Tom Phillips. In 1966, Phillips decided he would transform the next second-hand book he "could find for threepence" into art (Phillips, 2019). The book he stumbled upon was a seemingly forgotten 1892 Victorian novel called A Human Document by W. H. Mallock (Phillips, 2019). Phillips transformed each page of the book by circling and connecting words or phrases to tell a new poetic story, fading or blocking the rest away under layers of colour and artistic materials (Phillips, 2019). With several different iterations published between 1966 and the final version in 2016, A Humument has been Phillips' longest serial project (Phillips, 2019). In his discussion of Tristram Shandy, De Voogd (1988), briefly raises the example of A Humument as a work that similarly blurs the line between text and image as "co-existential" (p. 384). Portela (2014) likewise draws on the example of Phillips' work as a "multilayered verbal and pectoral structure" (p. 53). Although Portela (2014) even points out that Phillips' text "is given further depth by means of intertextual and parodic echoes of other texts and other paintings and drawings", he does not seem to push this further to explore Phillips' potential intertextual references to Sterne's work (p. 54). By neglecting to investigate the potential intertextual connections between the works of Sterne and Phillips, these scholars risk glossing over further messages to be found within the works that lie at the heart of their arguments.

At first glance, many pages in Phillips' work seem like they could be emulative of Sterne's visual experiments, such as those that make use of black and empty space to block out the text. In fact, black or blank space stand out as unusual in Phillips' work, given that most of his pages are quite visually layered and colourful. However, at least two pages in more recent iterations of Phillips' A Humument make explicit visual and textual allusions to Sterne. The first is the 2005 iteration of page 56 (Figure 2), which appears to frame the text within a marbled border (Phillips, 2005, p. 56). Here, it is as if Phillips has inverted Sterne's marbled page to 


\section{Bromberg / Resisting Linear Form}

decorate the margins rather than the text block. While the bottom half of the page appears to be caged behind marbled bars, Phillips' selected poetry hovers above as its own layer, as if free from these shackles. The design of this page revolves around the word "marble" circled in the center (Phillips, 2005, 56). Considering that this page is entitled "A Pause on the Landing", and since Phillips' selected poetry on this page makes repeated reference to stairs, this caged lower half of the page is more likely meant to evoke the shape of a marble staircase. This page appears to be highly connected to Sterne, designed for the Laurence Sterne Trust and even featured as the cover of volume 18 of the Shandean in 2007 (Figure 3). Notably, this appears to be the only cover of the Shandean, at least among those displayed on their website, to feature a reception piece rather than a marbled page from the original or reprints of Sterne's novel (International Laurence Sterne Foundation, 2018). In addition to the border's marbled pattern, the text that Phillips selects on this page perhaps also contributes to his attempt to connect himself and his work back through time to Sterne, such as through highlighting the phrase "with nothing between them but / time" (Phillips 2005, p. 56).

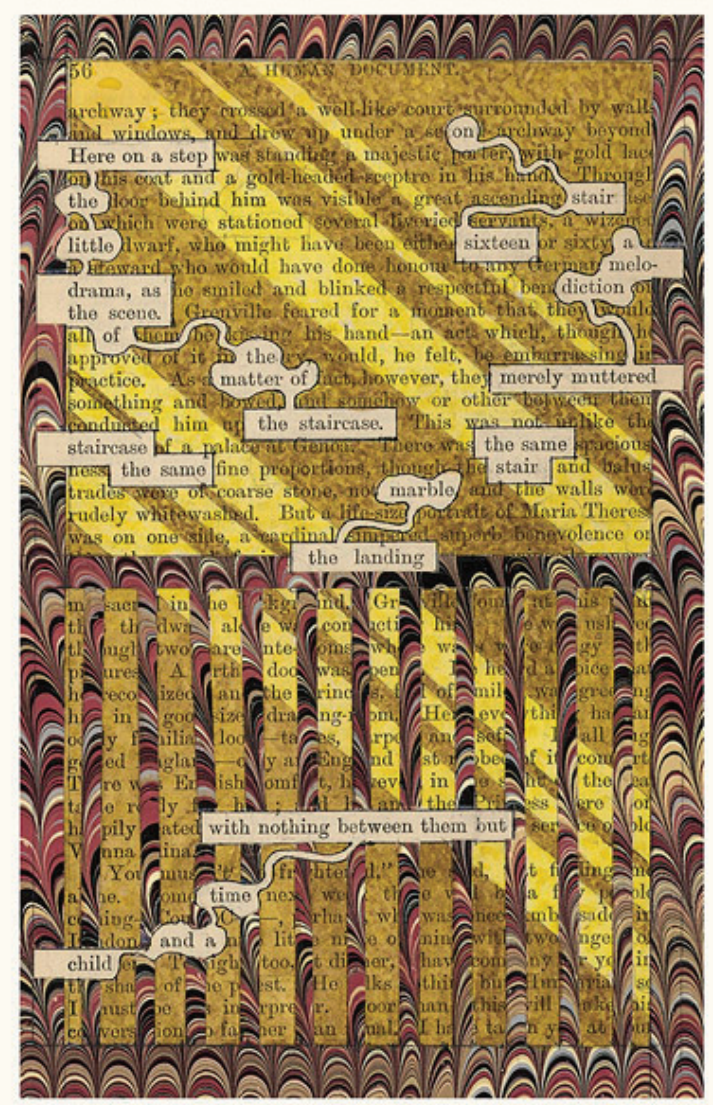

Figure 2: Page 56 of Tom Phillips' A Humument (Phillips, 2005).

(C) Tom Phillips, reprinted with permission. 


\section{Bromberg / Resisting Linear Form}

In another instance, on page 196 of the 2008 version of A Humument (Figure 4), Phillips makes an even more explicit reference to Sterne, given that the foot of the page reads "STERNE" in large block letters (Phillips, 2008, p. 196). Here, Sterne's name sits beneath a colourful cross that covers the page, perhaps hinting at the religious dimension of Sterne's life as a vicar (The Laurence Sterne Trust, 2010). This may be further emphasized by the grouped words "kind / minister" hovering above his name (Phillips, 2008, p. 196). The design resembles stained glass, adding to this potential religious reference. Filled with non-linear lines and noise, the colourful areas seem to be in tension with the restricting straight lines of the cross. This tension is also expressed in the text of the poem itself, which features some incomplete words, such as when Phillips" circles "separa / me" and "libera / me" (Phillips, 2008, p. 196). If Sterne is somehow the "kind / minister" referred to in the poem, Phillips seems to be asking for separation and liberation, to make what may be interpreted to mean his own artistic impact. This is perhaps best expressed through his choice to circle the words "so / I shall / make / my service" (Phillips, 2008, p. 196). In other words, the poem itself could be interpreted as some kind of message from Phillips to Sterne, in his attempt to emulate or recall his work and legacy. This page, among several others, likewise finds more official connection to Sterne by being exhibited and available for purchase at Shandy Hall, Sterne's home-turned-museum in Coxwold, maintained by the Laurence Sterne Trust (The Laurence Sterne Trust, 2010).

However, Phillips' work is emulative of Sterne not only through these visual and textual references, but also through its very form and design process. Phillips' A Humument is a highly iterative and experimental work, evident especially in the fact that its design had been an ongoing project over the course of fifty years (Phillips, 2019). Exploring the book online through Phillips' "Humument Slideshow", as opposed to in print, sheds extra light on the project's iterations. Each page displayed is accompanied by Phillips' first version from 1973, as well as the original untouched page from Mallock's novel (Phillips, 1973; 2005; 2008). In his afterword, Phillips (2016) reflects on the "inexhaustibility of even a single page", which Portela (2014) expands to the inexhaustibility of the codex as a medium more broadly (p. 65). Here, Phillips insinuates a certain palimpsestic quality to his work since; no matter how many times he approached the same page, he was able to find and produce a different poem and design. 


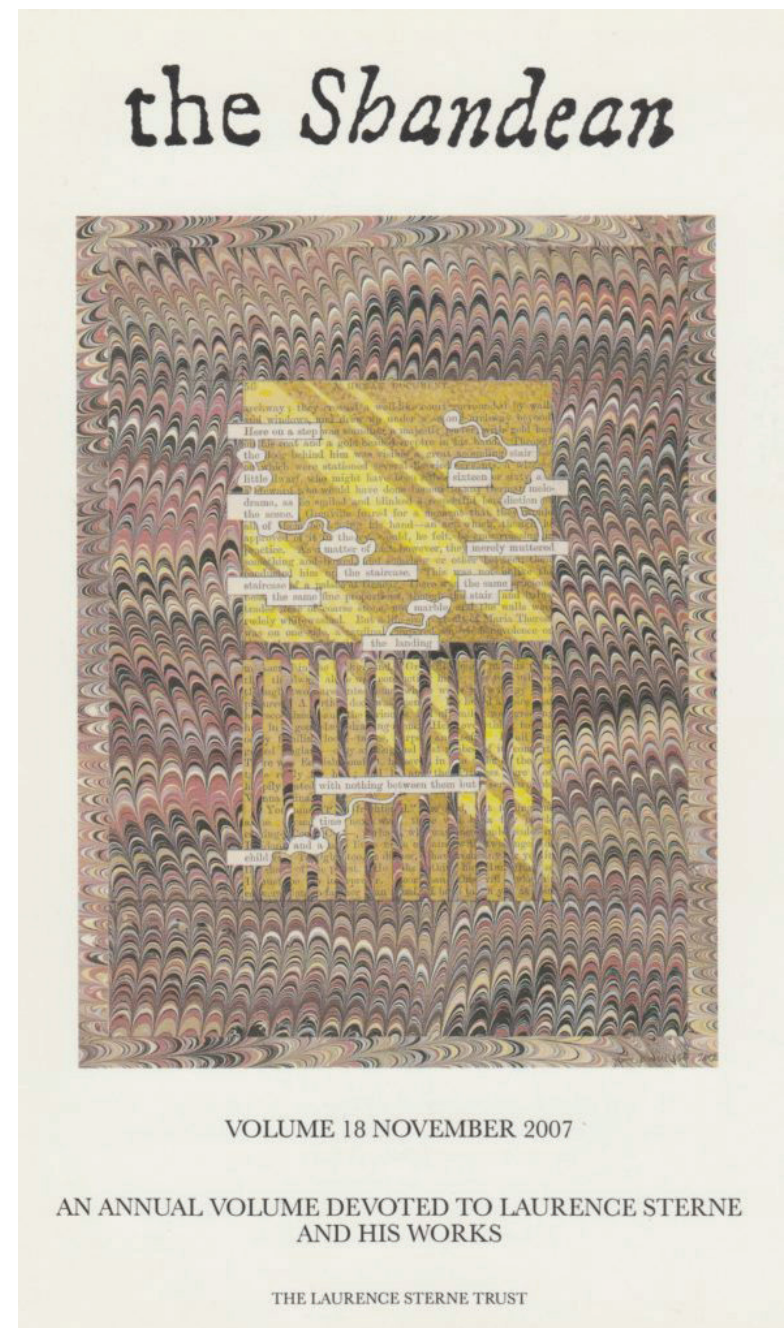

Figure 3: Tom Phillips' "A Pause on the Landing" featured on the cover of the Shandean, volume 18, 2007. (International Laurence Sterene Foundation, 2018). (C) The Shandean. Reprinted with permission of Peter De Voogd, chair of the International Sterne Foundation.

Consider for instance Phillips' own marbled page and how it seems to revolve around the word "marble" circled at its centre (Phillips, 2005, p. 56). The first version of this page has a completely different look, highlighting different words on the page that tell a different story. The word "marble" makes no appearance, and the reader would not even know it was there, since the layer of colour that blocks the text is not transparent (Phillips, 1973, p. 56). Likewise, the first version of page 196 draws no visual attention to Sterne's name (Phillips, 1973, p. 196). Like Sterne's marbled leaf, Phillips' A Humument seems to thrive off of a 'snowflake effect', which renders every iteration of the same page unique. Each of these pages and their various iterations can be read and interpreted in subjective ways. Therefore, through fostering a unique and challenging reading experience, the very form and creative process of Phillips' work also recalls Sterne's Tristram Shandy. 


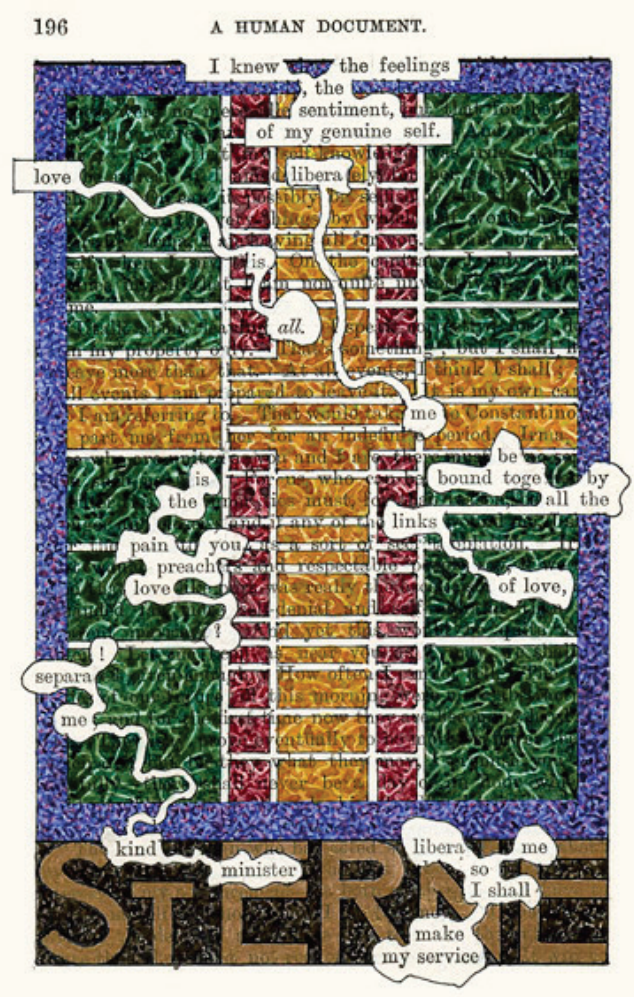

Figure 4: Page 196 of Tom Phillips' A Humument (Phillips, 2005).

(C) Tom Phillips, reprinted with permission.

\section{RESISTING LINEAR FORM}

The design of both Sterne's and Phillips' visual and textual experiments are governed by disorder and non-linearity. A central element that renders the reading experience of Phillips' poetry so subjective is its very shape. The words and phrases that Phillips chooses to highlight and connect along the page shift the reading experience, guiding the eyes not only left to right as they are used to, but also right to left, vertically or diagonally. In other words, the form of the poetry makes way for a less linear reading. This resistance to linear reading is similarly evident in Sterne's marbled page, and throughout Tristram Shandy as a whole. The random and disorderly pattern produced on each iteration of Sterne's marbled page reflects the non-linear and digressive style of the work as a whole, from the various other visual interruptions tucked throughout the volumes to the very style of Sterne's writing.

Consider, for instance, how Sterne skips chapters, frequently twists the narrative into long digressions, and does not even introduce his main character until the third volume of the novel (Sterne, 1761). Achieving a non-linear narrative appears to be a goal of Sterne's. This is quite perfectly represented by his squiggles in the sixth volume, or what De Voogd (2018) calls "a 


\section{Bromberg / Resisting Linear Form}

singular stroke of eloquence" (p. 76). The squiggles, as an interruption to the text, aim to visually represent the plotlines of the other volumes. Here, Sterne takes delight in disorder. As De Voogd (2018) points out, the squiggles and marbled page are similarly "lively", as they break free from the text and the expected form of the page (p. 83). This visual experiment is also of interest, considering that it was produced by Sterne himself, rather than through the hands of another artisan - as was the case for the marbled page (De Voogd, 2018, p. 76). Considering Sterne's marbled page through the lens of its reception, Phillips' A Humument brings into focus another interpretation of the page and its lasting impact in book history, as a visual tool which serves to resist a linear reading.

By actively aiming to achieve non-linearity through both textual and visual experiments, Sterne's work seems fairly radical for its time. Apparently, some audiences had trouble resonating with Sterne's strange experiments. In 1760, in response to his most recent serialization of Tristram Shandy, a group of clockmakers gathered in London to write an essay that called for the disparagement of Laurence Sterne and his famous novel. According to the clockmakers, an author should either "usefully instruct, or innocently amuse", which Sterne's "mere wildgoose chace [sic]" of a novel apparently fails to do (The Clockmakers, 1760, p. 7). Somehow, Sterne's novel made the lives of the clockmakers and their families "miserable" and therefore, they urged that the author should be looked upon with "detestation" (The Clockmakers, 1760, p. 10). The fact that the clockmakers as a unit felt compelled to take action by publishing this strongly-worded essay comes across as rather dramatic and strange. However, in doing so, they actually serve to perfectly demonstrate and reinforce how Sterne's work, as visualized through the marbled page, resists the conventions of literate culture.

In fact, there is likely no other cohort that could serve as a better example than clockmakers, as a profession that is inseparable from the linear concept of timekeeping. As Marshall McLuhan and his student Walter J. Ong argued, timekeeping is a product of literate culture. This is evident in Understanding Media, in which McLuhan (2005) dedicates an entire chapter to analyzing clocks (p. 157). Furthermore, in his study of oral and literate culture, Ong (2005) conceives of linear thought and speech as "artificial creations" that impose "strain on the psyche in preventing expression from falling into its more natural patterns" (p. 39). That is, according to Ong, the structure of thought and consciousness was once naturally more fluid, only to become increasingly more rigid and linear following the invention of writing and subsequent inventions like printing. Therefore, as professionals that could only belong to what Ong (2005) deems a culture of "secondary orality", exposed to writing and the technologies which followed, it is not surprising that the clockmakers felt threatened by or did not understand Sterne's novel (p. 2). Indeed, as Ong's reflection seems to imply, life and natural thought are not so linear and precise and by consequence, words can sometimes be insufficient to express the totality of the human experience. This is certainly evident through Sterne's and even Phillips' visual experiments. Through fostering an unusual, challenging, and non-linear reading experience, Sterne and likewise Phillips resist literate culture and its assumptions surrounding the form of the book and the practice of reading.

\section{CONCLUSION}

Even two hundred and sixty years later, a lot can still be said about a double-sided marbled leaf. As De Voogd (1988) says, each page of Tristram Shandy is a "living unit" and a "visual surprise" 


\section{Bromberg / Resisting Linear Form}

(p. 387). The many volumes of the novel serve as a collection of textual and visual digressions and experiments, lurking lurk behind the next page and waiting for the reader to happen upon them and feel something new - whether it be their first or a repeated encounter. Perhaps they will flip to discover the marbled page, in which they might find beauty, frustration, confusion, randomness, or even a reflection of themselves. Maybe they will be able to decipher its blots and waves of colour, or maybe they will feel and think nothing at all. In any case, the marbled page is there, in the middle of the book, to interrupt the text and it is unique in every volume and potentially in every reading. The marbled page demands a shift of the senses, from reading left to right to a more holistic visual analysis. It attempts to blend in with the text, constrained within the margins and with a page number almost just like the rest. Yet, it is also intensely aware of its own form and challenges the reader to question the very object they hold in their hands. New meaning can be found in this page not only through revisiting the same leaf, or exploring its many iterations, but also through considering its reception over time.

Although created hundreds of years apart, both Sterne's Tristram Shandy and Phillips' A Humument experiment with words and image to find delight in disorder and singularity. Therein lies the common message and reminder to their readers that is all too often surfed over by those grappling with these works. While our culture has become accustomed to expecting an introduction, body, and conclusion from any given narrative, Sterne's and Phillips' works serve as both textual and visual reminders that stories are not so simple or formulaic. They resist what a book and what an author is supposed to be by uncovering unpredictability, variation, and beauty within a precise form. In a culture that seems to have placed more value on the word over the image, Sterne and Phillips invite the reader back into their own naturally non-linear patterns of thought to experience the lost wonders of the visual. Perhaps the marbled page can be read and perhaps it carries a message, or maybe, it is irrational and messy, and that may be equally delightful.

\section{REFERENCES}

Barchas, J. (2003). Graphic design, print culture, and the eighteenth-century novel. Cambridge: Cambridge University Press.

Day, W. G. (1972). Tristram Shandy: The marbled leaf. The Library, s5-XXVII(2), 143-145.

De Voogd, P. J. (1985). Laurence Sterne, the marbledp page, and 'the use of accidents.' Word \& Image, 1(3), 279-287.

De Voogd, P. J. (1988). Tristram Shandy as aesthetic object. Word \& Image, 4(1), 383-392.

De Voogd, P. J. (2018). A singular stroke of eloquence: Tristram Shandy's typography. Nordic Journal of English Studies, 17(1), 74-84.

International Laurence Sterne Foundation. (2019). About ILSF. Retrieved from: http://shandean. org/ilsf/.

International Laurence Sterne Foundation. (2018, December 28). Marblings archives; marbled pages of the Shandean. Retrieved from: http://www.shandean.org/category/marblings/.

McLuhan, M. (2005). Understanding media: The extensions of man. London and New York: Taylor \& Francis e-Library.

Ong, W. J. (2005). Orality and literacy: The technologizing of the word. London and New York: 


\section{Bromberg / Resisting Linear Form}

Routledge, Taylor \& Francis e-Library.

Phillips, T. (2016). A Humument: A treated Victorian novel (Final Edition). New York: Thames and Hudson.

Phillips, T. (1973; 2005; 2008). Humument slideshow. Retrieved from: http://www.tomphillips. co.uk/humument/slideshow/1-50.

Phillips, T. (2019). Tom Phillips: Biography. Retrieved from: http://www.tomphillips.co.uk/ about.

Portela, P. (2014). Scripting reading motions: The codex and the computer as self-reflexive machines. Cambridge, MA: MIT Press.

Romney, R. (2014, July 15). Sterne's Tristram Shandy and materials as meaning [Blog]. Retrieved from: http://www.rebeccaromney.com/sternes-tristram-shandy-and-materialsas-meaning/.

Sterne, L. (1760). The life and opinions of Tristram Shandy, gentleman (second edition, Vol. I). London: Printed for R. and J. Dodsley.

Sterne, L. (1761). The life and opinions of Tristram Shandy, gentleman (Vol. III). London: Printed for R. and J. Dodsley.

Sterne, L. (1883). The life and opinions of Tristram Shandy, gentleman. London: George Routledge and Sons, Limited.

The Clockmakers outcry against the author of The life and opinions of Tristram Shandy. Dedicated to the most humble of Christian prelates. (1760). London: Printed for J. Burd.

The Laurence Sterne Trust. (2010). Shandy Hall. Retrieved from https://www.laurencesternetrust. org.uk/shandy-hall.php.

Wolfe, R. J. (1991). Marbled paper: Its history, techniques, and patterns: with special reference to the relationship of marbling to bookbinding in Europe and the Western World. Philadelphia: University of Pennsylvania Press. 